\title{
Gaitada gizli kan testi pozitifliği nedeni ile kolonoskopi yapılan hastaların kolonoskopik ve patolojik sonuçlarının değerlendirilmesi
}

\author{
Evaluation of colonoscopic and pathological outcomes of patients who have undergone \\ colonoscopy with a positive fecal occult blood screening test
}

\author{
Özlem Gül UTKU, Bilal ERGÜL, Dilek OĞUZ \\ Kırıkkale Üniversitesi Tıp Fakültesi, Gastroenteroloji Bölümü, Kırıkkale
}

\begin{abstract}
Giriş ve Amaç: Kolorektal kanser taramasında gaitada gizli kan testi dışında, fekal immünokimyasal test, fleksible sigmoidoskopi ve kolonoskopi kullanılan diğer yöntemlerdir. Bu çalışmada gaitada gizli kan testi pozitif olması nedeni ile kolonoskopi istenmiş olan hastaların kolonoskopik ve patolojik bulgularını değerlendirmeyi amaçladık. Gereç ve Yöntem: Bu çalışmaya Haziran 2014-Ekim 2016 yılları arasında gaitada gizli kan testi pozitif saptanan ve kolonoskopi yapılması için Ahi Evran Üniversitesi Eğitim ve Araştırma Hastanesi endoskopi ünitesine yönlendirilen hastalar alındı. Yetersiz kolon temizliği, aktif hematokezyası, kolon operasyonu öyküsü, inflamatuvar barsak hastalığı öyküsü veya üst gastrointestinal sistem endoskopisinde kanamaya neden olabilecek lezyonu olan hastalar çalışma dışı bırakıldı. Hastaların yaşları, cinsiyetleri, kolonoskopik bulguları, patoloji sonuçları not edildi. Üç ya da daha fazla polip, $1 \mathrm{~cm}$ 'den büyük adenomatöz polip, patolojik incelemede villöz komponent içeren ya da yüksek dereceli displazi saptanan hastalar yüksek riskli grup olarak değerlendirildi ve bu kriterlere göre kolon kanser tarama programına alındı. Bulgular: Çalışmaya toplam 225 hasta dâhil edildi. Hastaların 111'i (\%49.3) erkek, 114'ü (\%50.7) kadın, ortalama yaşları 58.52 (24-90), ortalama hemoglobin düzeyi 13.63 (7.2-18) idi. Endoskopik taniları; normal kolonoskopik bulgular 86 (\%38,2), polip 59 $(\% 26,2)$, yalnızca perianal hastalık 27 (\%12), divertikül $16(\% 7,1)$, koIon kanseri $14(\% 6,2)$, inflamatuvar barsak hastalığı $14(\% 6,2)$, enfeksiyöz kolit $6(\% 2,7)$, anjiodisplazi $3(\% 1,3)$ hasta şeklinde idi. Endoskopik olarak kolon kanseri düşünülen ve polip saptanan $73(\% 32,4)$ hastanın patoloji sonuçları; tübüler adenom $31(\% 42,5)$, adenokarsinom 17 (\%23,3), hiperplastik polip $16(\% 21,9)$, tübülovillöz adenom 7 (\%9,6), serrated adenom $2(\% 2,7)$ şeklinde değerlendirildi. Kolonoskopik olarak polip saptanan $3(\% 5,08)$ hastanın patolojisinde erken evre karsinom saptandı. Polip saptanan 59 hastanın 30'u (\%50,8) yüksek riskli, 29'u $(\% 49,2)$ düşük riskli olarak bulundu. Sonuç: Gaitada gizli kan testi pozitifliği ile gelen hastaların yaklaşık yarısında kolon patolojisi tespit edilmiştir. Bu test, kolon kanseri ve öncül lezyonlarının tespitinde olduğu gibi, subklinik inflamatuvar barsak hastalığı, kronik kan kaybına yol açan divertikül, anjiodisplazi gibi patolojilerin de tespitinde yardıma olan ucuz, kolay uygulanabilir bir yöntemdir.
\end{abstract}

Anahtar kelimeler: Gaitada gizli kan testi, kolonoskopi, kolorektal kanser, polip

\section{GíRis}

Kolorektal kanserler dünyada üçüncü sıklıkta karşılaşılan ve kansere bağlı ölümlerin önde gelen nedenlerinden biridir (1). Tarama programları sayesinde erken evre
Background and Aims: Methods such as guaiac fecal occult blood-screening test, fecal immunological test, colonoscopy, and sigmoidoscopy are generally used in colorectal screening programs. The aim of this study was to evaluate the colonoscopic and pathological findings of patients with a g-fecal occult blood-screening test-positive result. Materials and Methods: This study was conducted between June 2014 and October 2016 on patients who were referred to Ahi Evran University Training and Research Hospital endoscopy unit after a positive stool blood test and then underwent colonoscopy. The exclusion criteria were inadequate colon cleansing, active hematochezia, a history of colonic surgery, inflammatory bowel disease, or any lesion that may lead to hemorrhage in the upper gastrointestinal system. Age, sex, and colonoscopic and pathological findings of the study participants were recorded. Patients with three or more polyps, an adenomatous polyp measuring $>1 \mathrm{~cm}$ in diameter, pathological examination involving the villous component, or high-grade dysplasia were evaluated as the high-risk group. These patients attended the colon cancer screening program. Results: A total of 225 patients, including 111 (49.3\%) males, were recruited in the study. The mean age was 58.52 (range: 24-90) years. Mean hemoglobin levels were 13.63 (range: 7.2-18) $\mathrm{g} / \mathrm{dl}$. Endoscopic findings of these patients included normal colonoscopy [86 patients (38.2\%)], polyps [59 patients (26.2\%)], perianal disease [27 patients (12\%)], diverticulum [16 patients (7.1\%)], colon cancer [14 patients (6.2\%)], inflammatory bowel disease [14 patients (6.2\%)], infectious colitis [6 patients (2.7\%)], and angiodysplasia [3 patients (1.3\%)]. Pathological findings of 73 (32.4\%) patients who were diagnosed with colon cancer and polyps through endoscopy were as follows: tubular adenoma [31 patients (42.5\%)], adenocarcinoma [17 patients (23.3\%)], hyperplastic polyps [16 patients (21.9\%)], tubulovillous adenoma [ 7 patients $(9.6 \%)$ ], and serrated adenoma [2 patients $(2.7 \%)]$. Early-stage carcinoma was diagnosed in the pathology of 3 (5.08\%) patients who had colonoscopically detected polyps. Of the 59 patients who were diagnosed with polyps, 30 (50.8\%) patients were at high risk and 29 (49.2\%) were at low risk. Conclusion: Colonic pathology was detected in about half of the patients positive for $\mathrm{g}$-fecal occult blood-screening test. This test is not only an inexpensive and easily applicable method for colon cancer screening, but it is also helpful for the detection of pathologies that could lead to chronic blood loss, such as subclinical inflammatory bowel disease, diverticulitis, and angiodysplasia.

Key words: Fecal occult blood screening test, colonoscopy, colorectal cancer, polyp

kolorektal kanserler ve prekanseröz lezyonların tespiti ile sağ kalım oranları artmaktadır. Tarama programı için uygulanacak yöntem invaziv olmayan, yüksek duyarlıık 
ve özgüllüğe sahip, güvenilir, kullanışlı ve maliyet etkin olmalıdır. Kolorektal tarama programları ülkelere göre değişmektedir. Taramada kullanılan invaziv ve invaziv olmayan testler mevcuttur. Dışkıda gizli kan testi (GGK), dışkı immünokimyasal testi (FIT), fekalbazlı DNA testi ve kan bazlı DNA testi (SEPT9 testi) noninvaziv testlerdir. Invaziv testler ise sigmoidoskopi ve kolonoskopidir. Kolonoskopi lezyonun direk tespiti ve biyopsi alınmasına olanak sağladığı için diğer testlere üstün olmakla beraber invaziv bir yöntemdir. Kolonoskopi Amerika Birleşik Devletleri, Almanya, Polonya ve İtalya gibi ülkelerde birinci basamak tarama testi programına alınmışır. FIT ve DNA bazlı testler daha hassas yöntemler olmalarına rağmen, Fransa, Finlandiya ve İngiltere gibi ülkelerde GGK testi maliyet etkin olması nedeni ile hala tarama testi olarak kullanılmaktadır. Diğer Avrupa ülkelerinde GGK yerine FIT testi kullanılmaya başlanmıştır (2).

Gaitada gizli kan testi uzun zamandır kolorektal kanser tarama programlarında kullanılmaktadır. Birçok çalışmada sensitivite \%12.9-\%79.4, spesifitesi \%86.7-\%97.7 oranları arasında gösterilmiştir (3). GGK testinin dezavantajı üst ve alt gastrointestinal kanamaları ayırt edememesi ve diyetteki birçok faktörden etkilenmesidir. Buna rağmen, kolay uygulanabilir olması ve maliyet etkin olması nedeni ile ülkemizde tarama programlarında birinci sırada kullanılmaktadır. Bu çalışmada GGK testi pozitif olması nedeni ile kolonoskopi istenmiş olan hastaların kolonoskopik ve patolojik bulgularını değerlendirmeyi amaçladık.

\section{GEREÇ ve YÖNTEM}

Bu çalışmaya Haziran 2014-Ekim 2016 yılları arasında gaitada gizli kan testi pozitif saptanan ve kolonoskopi yapılması için Ahi Evran Üniversitesi Eğitim ve Araştırma Hastanesi endoskopi ünitesine yönlendirilen hastalar alındı. Yetersiz kolon temizliği, aktif hematokezyası, koIon operasyonu öyküsü veya inflamatuvar barsak hastalığı öyküsü olan, üst gastrointestinal sistemde erozyon, ülser ve malign lezyon tespit edilen hastalar çalışma dışı bırakıldı. Hastaların yaşları, cinsiyetleri, kolonoskopik bulguları, patoloji sonuçları not edildi. Üç ya da daha fazla polip, $1 \mathrm{~cm}$ 'den büyük adenomatöz polip, patolojik incelemede villöz komponent içeren ya da yüksek dereceli displazi saptanan hastalar yüksek riskli grup olarak değerlendirildi ve bu kriterlere göre kolon kanser tarama programına alındı.

\section{BULGULAR}

Çalışmaya toplam 225 hasta dâhil edildi. Hastaların 111'i (\%49.3) erkek, 114'ü (\%50.7) kadın, ortalama yaşları 58.52 (24-90), ortalama hemoglobin düzeyi 13.63 (7.2-
18) idi. Endoskopik tanıları; normal kolonoskopik bulgular $86(\% 38,2)$, polip $59(\% 26,2)$, yalnızca perianal hastalık $27(\% 12,1)$, divertikül $16(\% 7,1)$, kolon kanseri $14(\% 6,2)$, inflamatuvar barsak hastalı̆ı $14(\% 6,2)$, enfeksiyöz kolit $6(\% 2,7)$, anjiodisplazi $3(\% 1,3)$ hasta şeklinde idi (Tablo 1). Endoskopik olarak kolon kanseri düşünülen ve polip saptanan $73(\% 32,4)$ hastanın patoloji sonuçları; tübüler adenom $31(\% 42,5)$, adenokarsinom $17(\% 23,3)$, hiperplastik polip $16(\% 21,9)$, tübülovillöz adenom $7(\% 9,6)$, serrated adenom $2(\% 2,7)$ şeklinde değerlendirildi (Tablo 2). Kolonoskopik olarak polip saptanan $3(\% 5,08)$ hastanın patolojisinde erken evre karsinom saptandı. Polip saptanan 59 hastanın 30'u $(\% 50,8)$ yüksek riskli, 29 'u $(\% 49,2)$ düşük riskli olarak bulundu.

\section{Tablo 1. Kolonoskopi bulguları}

\begin{tabular}{|l|c|}
\hline Kolonoskopi Bulguları & N (\%) \\
\hline Normal kolonoskopik bulgular & $86(\% 38,2)$ \\
\hline Polip & $59(\% 26,2)$ \\
\hline Perianal hastalık & $27(\% 12,1)$ \\
\hline Divertikül & $16(\% 7,1)$ \\
\hline Kolon kanseri & $14(\% 6,2)$ \\
\hline İnflamatuvar barsak hastalığı & $14(\% 6,2)$ \\
\hline Enfeksiyöz kolit & $6(\% 2,7)$ \\
\hline Anjiodisplazi & $3(\% 1,3)$ \\
\hline
\end{tabular}

\begin{tabular}{|l|c|}
\hline Tablo 2. Patoloji Bulguları & \\
\hline Patoloji Bulguları & $\mathbf{N}(\%)$ \\
\hline Tubuler adenom & $31(\% 42,5)$ \\
\hline Adenokarsinom & $17(\% 23,3)$ \\
\hline Hiperplastik polip & $16(\% 21,9)$ \\
\hline Tubulovillöz adenom & $7(\% 9,6)$ \\
\hline Serrated adenom & $2(\% 2,7)$ \\
\hline
\end{tabular}

\section{TARTIŞMA}

Gaitada gizli kan testi gastrointestinal sistemin herhangi bir noktasından kaynaklanan kanamayı gösteren bir testtir. Daha çok anemi etiyolojisi araştırılırken veya koIon kanseri tarama programlarında kullanılır. GGK testi Guaiac metodu olarak adlandırılır. Guaiac reaksiyonu ortotoluidin, ortodonisidine ve benzidin gibi indikatörleri kullanan kimyasal bir metod olup, bu yöntemle 10 ml'den az kanamaları tespit etmek mümkündür. GGK tespiti için geçmişte farklı yöntemler kullanılmakla beraber günümüzde Guaiac ve immunokimyasal yöntemler kullanılmaktadır. Guaiac metodu, çeşitli modifikasyonlarla sensitif bir test haline getirilmiş olsa da, hem grubunun peroksidaz benzeri aktivitesini (psödoperoksidaz) belirle- 
meye dayalı bir test olduğundan spesifitesi düşüktür. Bu yöntem, intakt hemoglobine ve aynı zamanda serbest hale gelmiş hem grubuna duyarlı olmanın yanı sıra, peroksidaz aktivitesine sahip bütün moleküllerden ve yiyeceklerden etkilenir. Bu nedenle test yapılmadan birkaç gün önce yalancı pozitifliğe neden olabilecek kırmızı et, şalgam, turp, lahana, karnabahar, brokoli, elma, muz ve demir tedavisi gibi peroksidaz aktivitesi taşıyan besinlerin kesilmesi gerekir. Bol narenciye tüketilmesi ve $C$ vitamini alımı testi yalancı negatif hale getirebilir $(4,5)$.

Gastrointestinal kanserin önlenmesi, ölüm oranının azaltılması, prekanseröz lezyonların radikal tedavisi ve erken evre kanserlerin tespiti asemptomatik bir popülasyonun taranması yoluyla olur. Kolorektal kanser tarama programları ile mortalite ve morbiditenin azaldığını gösteren çalışmalar mevcuttur (6). Gaitada gizli kan testinin sensitivite ve spesifitesi düşük olsa da bazı ülkelerde 40 yaş bazılarında ise 50 yaş üzeri insanların bu testi yılda birkez, ailesinde kolon kanseri olan bireylerin bu testi daha erken dönemde yaptırması gereklidir. Bu test pozitif tespit edildiğinde kolonoskopik ve endoskopik değerlendirme yapılmalıdır.

Literatürde Amerika Birleşik Devletleri, Danimarka ve Büyük Biritanya'da Guaiac metodu ile tarama yapılan, uzun süreli kontrollü üç adet çalışma mevcuttur. Bu çalışmalarda hastalara sırasıyla 13, 10, 8 yıllık takiplerinde yılda 3 kez GGK takibi yapılmış. GGK testi taraması ile hastaların kolorektal kanserden ölüm oranlarının azalabileceği belirtilmiş. Bu üç çalışmada ölüm oranlarında azalma sırasıyla \%33, \%18, \%15 olarak tespit edilmiş ve kolorektal kanser taramasında ucuz ve etkili bir yöntem olabileceği belirtilmiştir (7-9). GGK pozitif çıkan hastaların yaklaşık \%60'ında kolonoskopik bulgular normaldir, ancak bu bulgulara sahip kişilerin nasıl takip edilmesi gerektiği konusunda fikir birliği yoktur. Danimarka ve Hollanda'da 8-10 yıl sonra tarama yapmak önerilse de İngiltere'de 2 yilda bir yapılmaktadır (10).

Paimela ve arkadaşlarının yaptıkları çalışmada GGK pozitif tespit edilen hastalar arasında invaziv kolorektal kanser tespit oranı $\% 8,2$, adenom ve kolorektal mukozal invazyon gösteren kanser oranı ise \%39,7 olarak tespit edilmiştir. Bu gruptaki hastalardan 2 tanesinde GGK pozitif olmasına rağmen kolonoskopi normal olarak rapor edilmiş, ilerleyen süreçte bu iki hastada sonraki kolonoskopide kanser tespit edilmiştir. Kolonoskopinin yetersizlik oranı \%0,3 olarak tespit edilmiştir (11). Brenner ve arkadaşlarının yapmış oldukları toplum kökenli çalışmada kolorektal kanser tarama programına alınan bireyler değerlendirilmiş. GGK pozitif tespit edilen bireyler ile negatif tespit edilen bireylerin kolonoskopik bulguları değerlendirildiğinde GGK pozitif tespit edilen bireylerde kolorektal kanser daha sık bulunmuş (12). IJspeert ve arkadaşlarının yapmış oldukları kohort çalışmada Ingiltere, İspanya, İtalya, Hollanda ve Polonya'da tarama programlarındaki veriler değerlendirilmiş ve serrated adenom ve eşlik eden adeomatöz polip oranları değerlendirilmeye alınmış. İngiltere'de GGK, İspanya ve İtalya'da fekal immünohistokimyasal test, Hollanda ve Polonya'da kolonoskopi tarama programı olarak kullanılmış. İngiltere'de 2009-2015 yılları arasında GGK testi tarama programına alınan 205.949 hastanın kolonoskopi bulguları değerlendirilmiş. Adenomatöz polip \%43 oranında tespit edilirken serrated polip \%15,3 olarak tespit edilmiş. Primer taramada kolonoskopi kullanan kohortlar ile GGK temelli tarama kullanan kohortların serrated adenom tespit oranları benzer bulunmuş (13). Andreas ve arkadaşlarının yapmış oldukları çalışmada GGK pozitif olan 26.123 kişiye kolonoskopi planlanmış 385 kişi daha önce kolorektal kanser tanısı almaları nedeni ile çalışma dışı bırakılmış. Kolonoskopik taramaya alınan bireylerin yaklaşık \% $\%$ 'inde kolorektal kanser, \%15'inde adenoma, \%15'inde diğer kolorektal patolojiler ve \%65'inde negatif kolonoskopik bulgular tespit edilmiş (10). Steele ve arkadaşlarının Birleşik Krallıkta yapmış oldukları tarama programlı çalışmada hastalar 2 yıllık tarama programına alınmış, ilk turda 167.415 , 2. turda 164.077 , 3. turda 175.583 birey tarama programına girmeyi kabul etmiş. Bireylere GGK testi uygulanmış, hem negatif çıkan gruba hem pozitif çıkan gruba kolonoskopi yapılmıs. Birinci turda GGK pozitif olan grupta kolorektal kanser tespit oranı \%12, adenom tespit oranı $\% 36,5$, yüksek riskli adenom tespit oranı $\% 4,3$ olarak tespit edilmiş. İinci turda kolorektal kanser tespit oranı \%7, adenom tespit oranı \%30,3, yüksek riskli adenom tespit oranı \%3,1 olarak tespit edilmiş. Üçüncü turda kolorektal kanser tespit oranı \%7,5, adenom tespit oranı \%29,1, yüksek riskli adenom tespit oranı \%3,1 olarak tespit edilmiş ve GGK'nın pozitif olması kolonoskopik tarama için önemli olduğu, ancak negatif çıkan hastaların da 2 yıllık tarama programlarına alınması vurgulanmıştır (14). Bizim çalışmamızda GGK'nın pozitif olması nedeni ile gastroenteroloji kliniğine gönderilen hastalar değerlendirmeye alındı. Kolonoskopide 17 hasta $(\% 7,5)$ kolorektal kanser tanısı aldı. Polip saptama oranımız ise $\% 26,2$ idi, \%50,2 hastada normal kolonoskopik bulgular ve perianal hastalık mevcuttu, \%17,3 hastada diğer kolonoskopik bulgular mevcuttu. Bizim grubumuz literatürdeki gruplara kıyasla daha küçük bir grup olmakla beraber polip, kolorektal kanser tespit oranları literatürle uyumludur. Literatürde, GGK testi ile ilgili çalışmalar toplum bazlı kolon kanseri tarama programlarına dahil edilen bireylerin verilerini içermekte ve çoğunlukla prekanseröz 
lezyonlar ve kolorektal kanserlerin tespit oranlarını yansıtmaktadır. Çalışmamızda GGK testi, kolon kanseri ve öncül lezyonlarının tespitinde olduğu gibi, subklinik inflamatuvar barsak hastalığı, kronik kan kaybına yol açan divertikül, anjiodisplazi gibi patolojilerin de tespitinde yardımcı olan ucuz, kolay uygulanabilir bir yöntem olarak değerlendirilmiştir.

\section{KAYNAKLAR}

1. Maida M, Macaluso FS, laniro G, et al. Screening of colorectal cancer: present and future. Expert Rev Anticancer Ther 2017;17:113146.

2. Issa IA, Noureddine M. Colorectal cancer screening: An updated review of the available options. World J Gastroenterol 2017;23:508696.

3. Lieberman DA. Clinical practice. Screening for colorectal cancer. N Engl J Med 2009;361:1179-87.

4. Bond JH. Fecal occult blood tests in occult gastrointestinal bleeding. Semin Gastrointest Dis 1999;10:48-52.

5. Allison JE. Review article: faecal occult blood testing for colorectal cancer. Aliment Pharmacol Ther 1998;12:1-10.

6. Yang H, Ge Z, Dai J, et al. Effectiveness of the immunofecal occult blood test for colorectal cancer screening in a large population. Dig Dis Sci 2011;56:203-7.

7. Mandel JS, Bond JH, Church TR, et al. Reducing mortality from colorectal cancer by screening for fecal occult blood. Minnesota Colon Cancer Control Study. N Engl J Med 1993;328:1365-71.

8. Hardcastle JD, Justin TA. Screening high-risk groups for colorectal neoplasia. Am J Gastroenterol 1996;91:850-2.
Sonuç olarak, gaitada gizli kan testi maliyet etkin olması, kolay uygulanabilir olması nedeni ile ülkemizde de bazı Avrupa ülkelerinde olduğu gibi asemptomatik bireylerin toplum kökenli tarama programlarında birinci sırada kullanılmalıdır. Ancak negatif GGK testi birey bazlı düşünüldüğünde kolonoskopik taramaya engel olmamalıdır.

9. Kronborg O, Fenger C, Olsen J, et al. Randomised study of screen ing for colorectal cancer with faecal-occult-blood test. Lancet 1996;348:1467-71.

10. Bjerrum A, Andersen O, Fischer A, et al. Long-term risk of colorectal cancer after negative colonoscopy in a Danish gFOBT screening cohort. Int J Cancer 2017;141:503-11.

11. Paimela $H$, Malila N, Palva $T$, Hakulinen $T$, Vertio $H$, Jarvinen $H$. Early detection of colorectal cancer with faecal occult blood test screening. Br J Surg 2010;97:1567-71.

12. Brenner $H$, Hoffmeister M, Birkner B, Stock C. Men with negative results of guaiac-based fecal occult blood test have higher prevalences of colorectal neoplasms than women with positive results. Int J Cancer 2014;134:2927-34.

13. IJspeert JEG, Bevan R, Senore C, et al. Detection rate of serrated polyps and serrated polyposis syndrome in colorectal cancer screening cohorts: a European overview. Gut 2017;66:1225-32.

14. Steele RJ, McClements PL, Libby G, et al. Results from the first three rounds of the Scottish demonstration pilot of FOBT screening for colorectal cancer. Gut 2009;58:530-5. 